\title{
Protective effects of Tougu Xiaotong capsule on tumor necrosis factor- $\alpha$-injured UMR-106 cells
}

\author{
NAISHUN LIAO ${ }^{1 *}$, YUNMEI HUANG ${ }^{1-3^{*}}$, JINXIA YE $^{1,2}$, WENLIE CHEN $^{1-3}$, ZUAN FANG LI $^{1-3}$, \\ RUHUI LIN ${ }^{1-3}$, XIHAI LI ${ }^{1}$, LIANGPU ZHENG ${ }^{1,2}$ and XIANXIANG LIU ${ }^{1,2}$ \\ ${ }^{1}$ Academy of Integrative Medicine, Fujian University of Traditional Chinese Medicine; \\ ${ }^{2}$ Fujian Key Laboratory of Integrative Medicine on Geriatrics, Fujian University of Traditional Chinese Medicine; \\ ${ }^{3}$ National Laboratory of Traditional Chinese Medicine Pharmacology (Cell Structure and Function), \\ Fujian Academy of Integrative Medicine, Fuzhou, Fujian 350122, P.R. China
}

Received September 26, 2014; Accepted August 5, 2015

DOI: $10.3892 /$ etm.2015.2739

\begin{abstract}
Tumor necrosis factor- $\alpha(\mathrm{TNF}-\alpha)$ plays an important role in the abnormal metabolism of osteoblasts (OBs), which leads to subchondral bone (SB) alterations in osteoarthritis. In the present study, Tougu Xiaotong capsule (TXC), a traditional Chinese medicine, was used to treat TNF- $\alpha$-injured OB-like cells. The cellular viability, mortality and ultramicroscopic morphology were evaluated. Thereafter, the activity of alkaline phosphatase (ALP), secretion of osteocalcin $(\mathrm{OCN})$ and mineralization of nodules were analyzed. The results showed that TXC treatment significantly promoted cell proliferation, reduced cellular mortality and improved cellular ultrastructure, particularly that of the endoplasmic reticulum and nucleus. These data indicate that TXC is able to promote cell growth, as well as prevent inflammation in OB-like cells. Furthermore, the activity of ALP, secretion of OCN and mineralization of nodules were accelerated, and the calcium content of the TNF- $\alpha$-injured OB-like cells was promoted by TXC treatment. These results indicate that TXC protected the OB-like cells from TNF- $\alpha$-induced injuries. This may be a potential mechanism through which TXC regulates SB remodeling in the clinical treatment of osteoarthritis.
\end{abstract}

\section{Introduction}

Osteoarthritis (OA) is a chronic joint disease, which occurs most often among older people and affects the whole joint

Correspondence to: Professor Wenlie Chen or Professor Xiangxian Liu, Academy of Integrative Medicine, Fujian University of Traditional Chinese Medicine, 1 Qiuyang Road, Fuzhou, Fujian 350122, P.R. China

E-mail: chen.wl@163.com

E-mail: liuxianxiang@163.com

${ }^{*}$ Contributed equally

Key words: osteoblast, proliferation, differentiation, tumor necrosis factor- $\alpha$, Tougu Xiaotong capsule structure. Although the details of the pathogenesis of OA are unclear, pathological changes are mainly observed in cartilage, subchondral bone (SB), the articular capsule and synovial membrane (1). OA has traditionally been considered a disease of cartilage; however, studies have demonstrated that the SB plays an important role in the disease (2-6), through the strong effect it has on shock absorption and cartilage metabolism, for example (7). Furthermore, the alterations in the SB, which are commonly involved in SB deterioration and sclerosis, may occur during or following cartilage changes, and can contribute to cartilage degradation in animal models $(2,6,8)$. SB alterations are therefore closely associated with the pathogenesis, initiation and progression of OA.

In addition to SB alterations, cytokines are also involved in the pathogenesis of OA. Catabolic cytokine tumor necrosis factor- $\alpha$ (TNF- $\alpha$ ) and interleukin-1 (IL-1), in particular, can modulate cartilage degradation and synovial inflammation. TNF- $\alpha$, as one of the major inflammatory mediators during the development of OA, has been found to be increased in osteoarthritic SB during the inflammatory process associated with the pathology of OA $(9,10)$. Furthermore, TNF- $\alpha$ has been demonstrated to injure osteoblasts (OBs) through the inhibition of cell proliferation and differentiation, as well as through the induction of apoptosis (11-14). These studies indicate that TNF- $\alpha$ may also be involved in the SB alterations that occur during the pathogenesis of OA.

Under pathological conditions, abnormal SB remodeling is the main cause of SB alterations, and therefore, regulating SB metabolism could slow down the progress of OA. OBs, which form major parts of the SB framework, are responsible for bone formation in the process of SB remodeling. Notably, SB OBs in patients with OA exhibit abnormal metabolism $(15,16)$, suggesting that the regulation of the osteogenic ability of OBs could contribute to SB metabolism.

Tougu Xiaotong capsule (TXC), which consists of Radix Morindae Officinalis, Radix Paeoniae Alba, Rhizoma Ligusticum Wallichii and Herba Sarcandrae Glabrae (17), has been used to treat OA in the Second People's Hospital Affiliated to Fujian University of Traditional Chinese Medicine (Fujian, China) for more than two decades. In our previous studies we 
found that TXC was able to reduce the rate and change the pattern of SB remodeling, leading to a reduction in SB sclerosis $(18,19)$; however, the molecular mechanism of the effect of TXC on SB remodeling remains unknown. A TNF- $\alpha$-injured OB-like cell line was therefore used to evaluate the protective effects of TXC on cell proliferation and differentiation and investigate the underlying mechanisms by which TXC affects $\mathrm{SB}$ remodeling in $\mathrm{OA}$.

\section{Materials and methods}

Reagents. Eagle's minimum essential medium, $\alpha$ modification ( $\alpha$-MEM), fetal bovine serum (FBS), phosphate-buffered saline (PBS) and $0.25 \%$ trypsin - $0.02 \%$ EDTA were HyClone products (GE Healthcare, Logan, UT, USA), 3-(4,5-dimethylthiazol-2-yl)-2,5-diphenyltetrazolium bromide (MTT) from Sigma Group Inc. (Cream Ridge, NJ, USA) and rat TNF- $\alpha$ was from PeproTech, Inc. (London, UK). Propidium iodide (PI), Hoechst 33258 and 4',6-diamidino-2-phenylindole were purchased from MP Biomedicals (Santa Ana, CA, USA), alizarin red $\mathrm{S}$ from Shanghai Sangon Biological Engineering Technology \& Services Co., Ltd. (Shanghai, China)., dimethyl sulfoxide (DMSO) from Shanghai Sinopharm Chemical Reagent Co., Ltd. (Shanghai, China) and tetracycline ointment from Beijing Solarbio Science \& Technology Co., Ltd. (Beijing, China). The alkaline phosphatase (ALP) test kit and osteocalcin (OCN) ELISA test kit were obtained from Nanjing Jiancheng Bioengineering Institute (Nanjing, China).

Cell culture. The OB-like cell line (UMR-106) was obtained from the type culture collection of the Chinese Academy of Sciences (Shanghai, China). Briefly, cells were cultured in $\alpha$-MEM containing $10 \%$ FBS supplemented with $1 \%$ penicillin/streptomycin at $37^{\circ} \mathrm{C}$ in a humidified atmosphere containing $5 \% \mathrm{CO}_{2}$. Once the cells had reached $\sim 80 \%$ confluence, they were detached using $0.25 \%$ trypsin $-0.02 \%$ EDTA, and diluted at 1:3.

TXC testing. TXC was obtained from the Second People's Hospital Affiliated to Fujian University of Traditional Chinese Medicine (Approval no. Ming Zhizi Z20100006). A $30 \mathrm{mg} / \mathrm{ml}$ stock solution of TXC was prepared by dissolving TXC power in PBS and storing it at $-20^{\circ} \mathrm{C}$. The working concentrations of TXC were diluted in the cell culture medium.

Cell viability assay. Cells were seeded into 96-well plates at a density of $1 \times 10^{4}$ cells/well in $0.1 \mathrm{ml}$ medium, and then treated with $30 \mathrm{ng} / \mathrm{ml} \mathrm{TNF}-\alpha$ as previously described $(20,21)$ or $30 \mathrm{ng} / \mathrm{ml}$ TNF- $\alpha$ plus various concentrations of TXC $(0.625$, 1.25 and $2.5 \mathrm{mg} / \mathrm{ml}$ ) for $24 \mathrm{~h}$. Subsequently, $100 \mu 10.5 \mathrm{mg} / \mathrm{ml}$ MTT solution was added to each well and the plates were incubated at $37^{\circ} \mathrm{C}$ for $4 \mathrm{~h}$; the purple-blue MTT formazan precipitate was then dissolved in $150 \mu 1$ DMSO. Finally, the absorbance was measured at $570 \mathrm{~nm}$ using an ELISA reader (ELX800; BioTek Instruments, Inc., Winooski, VT, USA).

Observation and analysis of cell death. A total of $1 \times 10^{5}$ cells were seeded into $35-\mathrm{mm}$-diameter Petri dishes in $1 \mathrm{ml}$ medium, and treated with $30 \mathrm{ng} / \mathrm{ml} \mathrm{TNF-} \alpha$ or $30 \mathrm{ng} / \mathrm{ml}$
TNF- $\alpha$ plus $1.25 \mathrm{mg} / \mathrm{ml} \mathrm{TXC}$ for $24 \mathrm{~h}$; at the end of the treatment, the live cells were stained by incubating with $10 \mu \mathrm{g} / \mathrm{ml}$ Hoechst 33258 solution at $37^{\circ} \mathrm{C}$ for $30 \mathrm{~min}$ in the dark, while the dead cells were stained by incubating with $10 \mu \mathrm{g} / \mathrm{ml} \mathrm{PI}$ at $37^{\circ} \mathrm{C}$ for another $10 \mathrm{~min}$. The staining solution was then discarded and, following supplementation with 0.1 mM PBS, the stained cells were examined under a fluorescence microscope (EVOS ${ }^{\text {Tм }}$ FL; Life Technologies, Carlsbad, CA, USA) and further observed using a laser scanning confocal microscope (LSCM; LSM 710; Zeiss, Oberkochen, Germany). All images were captured at a magnification of x200 and the cellular mortality was analyzed using the ZEN 2009 Light Edition imaging analysis system (Zeiss).

Cell ultrastructure evaluation. The cellular ultrastructure was observed using transmission electronic microscope (TEM; H-7650; Hitachi, Ltd., Tokyo, Japan). Cells were seeded into 6 -well plates at a density of $2 \times 10^{5}$ cells/well in $2 \mathrm{ml}$ medium, and treated with $30 \mathrm{ng} / \mathrm{ml} \mathrm{TNF}-\alpha$ or $30 \mathrm{ng} / \mathrm{ml} \mathrm{TNF}-\alpha$ plus $1.25 \mathrm{mg} / \mathrm{ml} \mathrm{TXC}$ for $24 \mathrm{~h}$; the cells were then scratched with $200 \mu 12.5 \%$ glutaraldehyde in $1 \mathrm{ml}$ fresh medium, collected and adjusted to the concentration of $1 \times 10^{6}$ cells $/ \mathrm{ml}$. The cells were then pre-fixed in $2.5 \%$ glutaraldehyde for $24 \mathrm{~h}$ at $4{ }^{\circ} \mathrm{C}$, rinsed with $0.1 \mathrm{mM}$ PBS 3 times, post-fixed in $1 \%$ osmic acid and $1.5 \%$ potassium hexacyanoferrate(II) for $1.5 \mathrm{~h}$ and then rinsed with $0.1 \mathrm{mM}$ PBS three more times. Next, the cells were stained with uranyl acetate-saturated $70 \%$ ethanol overnight at $4^{\circ} \mathrm{C}$, dehydrated in ethanol and acetone solution of ascending concentrations and embedded in epoxide resin 618. Furthermore, the embedded blocks were ultrasectioned into $90-\mathrm{nm}$ sections and stained with uranyl acetate and lead citrate for $10 \mathrm{~min}$, respectively. Finally, the stained ultrasections were observed using TEM at $80 \mathrm{kV}$.

Assay of ALP activity and OCN secretion. Cells were seeded into 24 -well plates at a density of $1 \times 10^{5}$ cells/well in $1 \mathrm{ml}$ medium, and then treated with $10 \mathrm{ng} / \mathrm{ml} \mathrm{TNF-} \alpha$ as previously described (22) or $10 \mathrm{ng} / \mathrm{ml} \mathrm{TNF}-\alpha$ plus $1.25 \mathrm{mg} / \mathrm{ml}$ TXC for 14 days. The supernatant was collected every 2 days and stored at $-80^{\circ} \mathrm{C}$ until it was finally analyzed using the ALP assay kit with colorimetric measurement using a semi-automatic biochemical analyzer (BA-88A; Mindray, Shenzhen, China). The secretion of OCN was evaluated using the ELISA kit, according to the manufacturer's instructions; briefly, the OCN standard and samples were added to the antibody-coated 96 wells, and incubated at $37^{\circ} \mathrm{C}$ for $1 \mathrm{~h}$; following repeated washes, the substrate was added to each well at $37^{\circ} \mathrm{C}$ for $15 \mathrm{~min}$; finally the absorbance was measured at $450 \mathrm{~nm}$ using the ELISA reader (BioTek Instruments, Inc.).

Optical morphology of mineralized nodules. Two methods, alizarin red $\mathrm{S}$ and tetracycline staining, were used to observe mineralized nodule formation. Cells were seeded into 6 -well plates at a density of $2 \times 10^{5}$ cells/well in $2 \mathrm{ml}$ medium, or medium containing $50 \mu \mathrm{g} / \mathrm{ml}$ tetracycline. After treating with TNF- $\alpha(10 \mathrm{ng} / \mathrm{ml})$ or TNF- $\alpha$ plus TXC $(10 \mathrm{ng} / \mathrm{ml}+1.25 \mathrm{mg} / \mathrm{ml}$, respectively) for 14 days, the cells were fixed with $4 \%$ paraformaldehyde at room temperature for $15 \mathrm{~min}$, rinsed with $0.1 \mathrm{mM}$ PBS and stained with alizarin red $\mathrm{S}$ at $37^{\circ} \mathrm{C}$ for $30 \mathrm{~min}$. The stained cells were observed 
using a phase contrast microscope (Eclipse TS-100F; Nikon Corporation, Tokyo, Japan) and the images were captured at a magnification of $x 40$. Tetracycline staining was observed using an LSCM (Zeiss) and the images were captured at a magnification of $\mathrm{x} 100$.

Calcium content of mineralized nodules. The calcium content was observed and analyzed using a scanning electron microscope (SEM; Hitachi TM3000; Hitachi, Ltd., Tokyo, Japan). A total of $2 \times 10^{5}$ cells were seeded into 6 -well plates, and treated with TNF- $\alpha(10 \mathrm{ng} / \mathrm{ml})$ or TNF- $\alpha$ (10 $\mathrm{ng} / \mathrm{ml}+1.25 \mathrm{mg} / \mathrm{ml}$, respectively) plus TXC for 14 days. The treated cells were pre-fixed in $2.5 \%$ glutaraldehyde for $24 \mathrm{~h}$ at $4^{\circ} \mathrm{C}$, rinsed with $0.1 \mathrm{mM}$ PBS three times and washed with distilled water for $30 \mathrm{sec}$, then immediately post-fixed in $1 \%$ osmic acid and $1.5 \%$ potassium hexacyanoferrate(II) at $4^{\circ} \mathrm{C}$ for $1.5 \mathrm{~h}$ and rinsed with $0.1 \mathrm{mM}$ PBS three more times. Subsequently, the rinsed cells were washed with distilled water for $30 \mathrm{sec}$, and then dehydrated in tert-butyl alcohol solution of ascending concentrations. They were then subjected to vacuum drying and were sputter-coated with platinum using IB-5 ion sputtering equipment (Eiko, Co., Ltd., Hitachinaka, Japan). Finally, mineralized nodules were observed using the SEM and the images were captured at a magnification of $x 400$. An energy dispersive spectroscopy (EDS; Quantax 70; Bruker, Berlin, Germany) analysis was performed in order to further examine the calcium content of mineralized nodules at a magnification of $x 5,000$.

Statistical analysis. GraphPad Prism ${ }^{\circledR} 6$ for Windows (GraphPad Software, Inc., La Jolla, CA, USA). was used for the statistical analysis. All quantitative data are expressed as the mean \pm standard deviation. Statistical analysis among different groups was carried out with the paired t-test. $\mathrm{P}<0.05$ was considered to indicate a statistically significant difference.

\section{Results}

TXC promotes cell proliferation. Following treatment with TXC for $24 \mathrm{~h}$, the viability of the injured cells was determined using MTT assay. As shown in Fig. 1, the cellular viability of the TNF- $\alpha$ group was significantly lower compared with that of the control group, indicating that TNF- $\alpha$ inhibited the viability of OB-like cells. The cell viability of the TXC groups was promoted when compared with that of the TNF- $\alpha$ group $(\mathrm{P}<0.01)$, suggesting that TXC protected the OB-like cells from TNF- $\alpha$-induced injury. Notably, $1.25 \mathrm{mg} / \mathrm{ml} \mathrm{TXC} \mathrm{had} \mathrm{a}$ markedly higher protective effect than the other concentrations of TXC, further implying that the protective role of TXC was not dose-dependent.

TXC reduces cell death. To further investigate the cell growth following TXC treatment, cellular mortality was examined using fluorescence microscopy and an LSCM. As shown in Fig. 2, the living cells (blue nuclei, stained with Hoechst 33258) were significantly fewer and the mean intensity significantly lower in the TNF- $\alpha$ group compared with those in the control group, but the number of dead cells (red nuclei, stained by PI) and mean intensity were significantly higher in the TNF- $\alpha$ group than in the control group. This



Figure 1. Effect of TXC on the viability of TNF- $\alpha$-injured OB-like cells. TXC treatment significantly promoted cell proliferation of the TNF- $\alpha$-injured OB-like cells compared with that of cells treated with TNF- $\alpha$ alone. The data were normalized to the viability of the control group (100\%) and gathered from at least three independent experiments. For all groups, $\mathrm{n}=6 .{ }^{* *} \mathrm{P}<0.01$; ${ }^{* * * *} \mathrm{P}<0.001$. TXC, Tougu Xiaotong capsule; TNF- $\alpha$, tumor necrosis factor- $\alpha$; $\mathrm{OB}$, osteoblast.

finding suggests that TNF- $\alpha$ is able to inhibit OB-like cell growth; however, the larger number of living cells and their higher mean intensity, as well as the smaller number of dead cells and their corresponding mean intensity that were observed in the TXC group when compared with the TNF- $\alpha$ group, clearly demonstrated that TXC prevented the OB-like cells from undergoing TNF- $\alpha$ injuries.

TXC improves cellular ultrastructure. To reveal the protective effects of TXC on cellular ultrastructure, TEM was used to observe the ultrathin sections of $\mathrm{OB}$-like cells following treatment with TNF- $\alpha$ and TXC for 24 h. As shown in Fig. 3, the cells of the control group were adherent with a long-fusiform shape, and the nucleus and chromatin were normal and had generally regular contours. By contrast, the TNF- $\alpha$-injured cells exhibited typical apoptotic characteristics, such as round shape, nuclear chromatin condensation, mitochondrial pyknosis and expansion of the endoplasmic reticulum. By contrast, the nucleus and other organelles of the TXC-treated cells appeared clearly improved following treatment, which indicated that TXC attenuated the TNF- $\alpha$-induced injuries of the OB-like cells.

TXC promotes ALP activity and OCN secretion. ALP is an early index and $\mathrm{OCN}$ a late-stage marker of $\mathrm{OB}$ differentiation; therefore, to further evaluate the effects of TXC on the progress of OB-like cell differentiation, the ALP activity and OCN secretion were determined once every 2 days, following the initial treatment for 14 days. As shown in Fig 4, ALP and OCN were significantly decreased in the TNF- $\alpha$ group compared with the control group between days 2 and 14 of differentiation, suggesting that TNF- $\alpha$ inhibited the differentiation of the OB-like cells. By contrast, the TXC group showed a significant increase in ALP activity and OCN secretion between days 2 
A

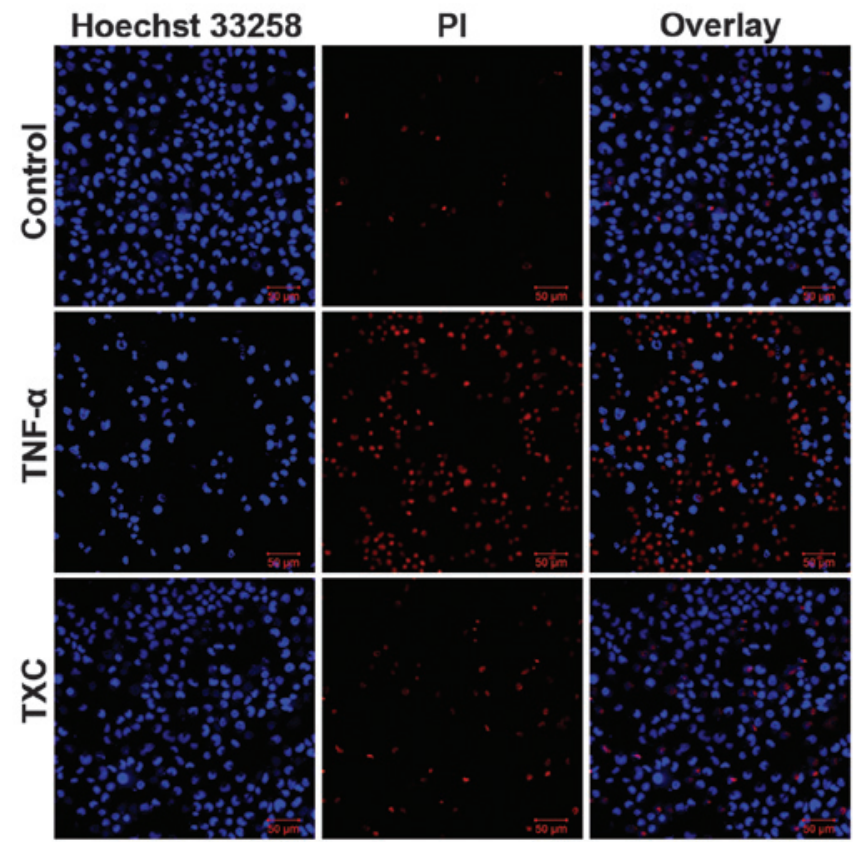

B

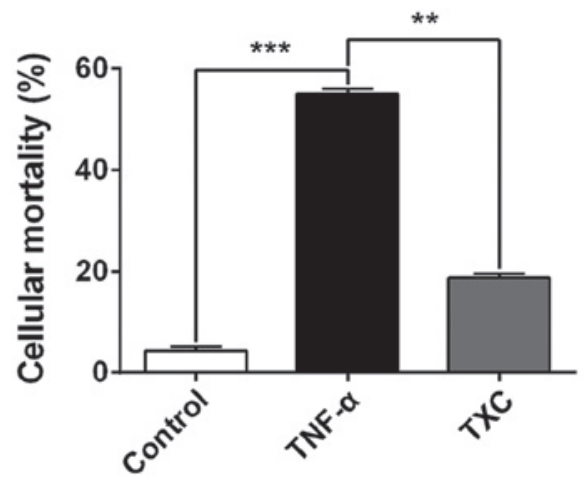

Figure 2. Effect of TXC on the death of TNF- $\alpha$-injured OB-like cells. Compared with the TNF- $\alpha$ group, the TXC group exhibited a significantly decreased cell death rate of the injured OB-like cells. (A) Images were taken from three independent experiments and captured at a magnification of x200. (B) Quantification of cell death analysis. For all groups, $\mathrm{n}=3 .{ }^{* *} \mathrm{P}<0.01 ;{ }^{* * *} \mathrm{P}<0.001$. TXC, Tougu Xiaotong capsule; TNF- $\alpha$, tumor necrosis factor- $\alpha$; OB, osteoblast; PI, propidium iodide.

$\mathbf{A}$

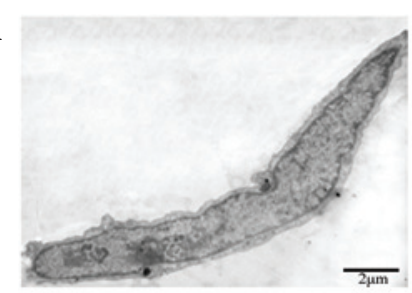

C

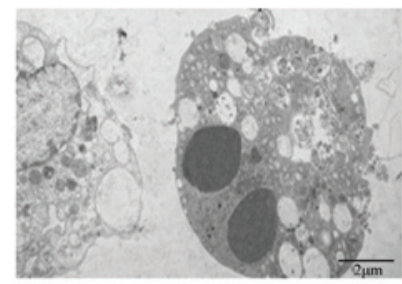

$\mathbf{E}$

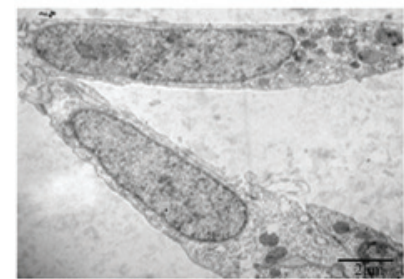

B

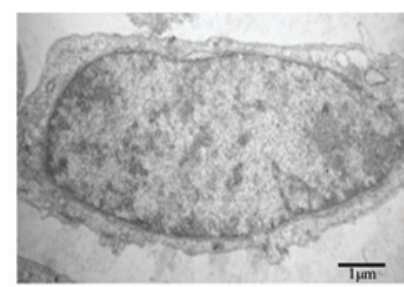

D

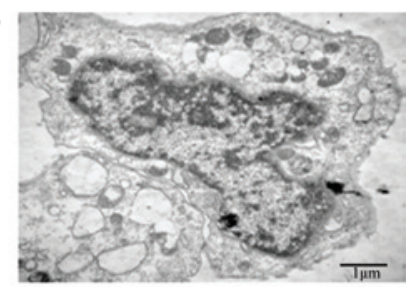

F

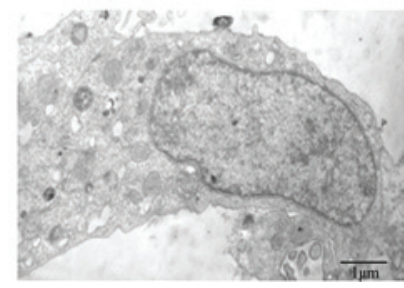

Figure 3. Effect of TXC on the cell ultrastructure of TNF- $\alpha$-injured OB-like cells. (A and B) The normal cells mainly presented a long fusiform shape and the nucleus and chromatin were normal with generally regular contours. (C and D) TNF- $\alpha$-injured OB-like cells showed typical apoptotic characteristics, and the nuclear chromatin and mitochondria, as well as the endoplasmic reticulum presented an abnormal ultrastructure. (E and F) TXC-treated OB-like cells also mainly presented a long fusiform shape, however, many of their organelles, including the nucleus, mitochondria and endoplasmic reticulum, appeared clearly improved following treatment. TXC, Tougu Xiaotong capsule; TNF- $\alpha$, tumor necrosis factor- $\alpha$; OB, osteoblast.

and 14 of differentiation compared with those in the TNF- $\alpha$ group, suggesting that TXC promoted differentiation of the TNF- $\alpha$-treated OB-like cells, partly through the upregulation of ALP activity and OCN secretion. Furthermore, ALP activity and OCN secretion were not decreased as the treatment time was extended, which indicates that the cell injuries did not persist for a prolonged period of time.

TXC promotes mineralized nodule formation and calcium secretion. Mineralized nodules, which contain large amounts 

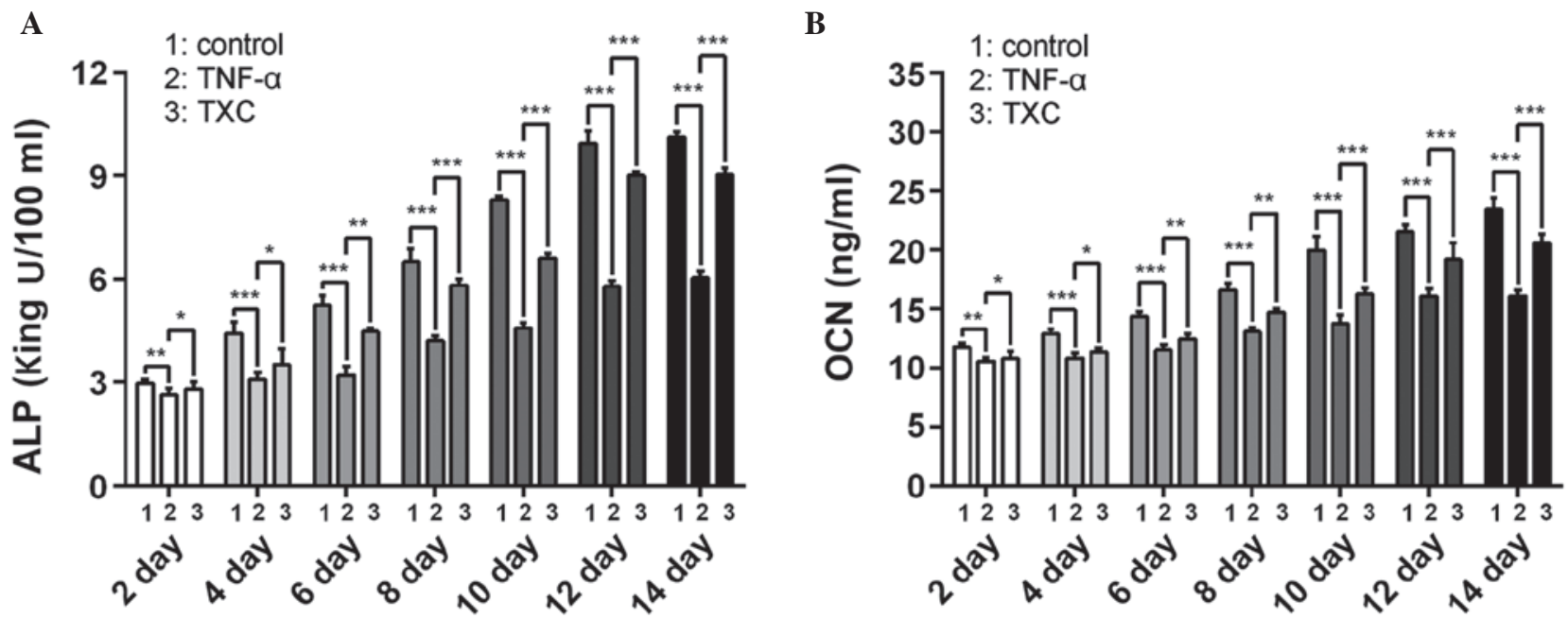

Figure 4. Effect of TXC on ALP activity and OCN levels in TNF- $\alpha$-injured OB-like cells. Compared with the TNF- $\alpha$ group, the TXC treatment significantly increased the (A) ALP activity and (B) OCN secretion of the injured OB-like cells. Data were gathered from at least three independent experiments. For all groups, $\mathrm{n}=6 .{ }^{*} \mathrm{P}<0.05 ;{ }^{* * *} \mathrm{P}<0.01 ;{ }^{* * * *} \mathrm{P}<0.001$. TXC, Tougu Xiaotong capsule; TNF- $\alpha$, tumor necrosis factor- $\alpha$; ALP, alkaline phosphatase; OCN, secretion of osteocalcin; OB, osteoblast.

A

a
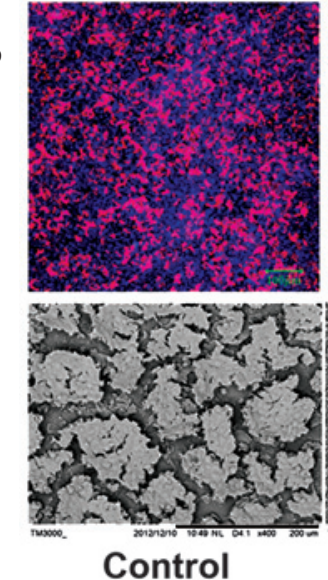
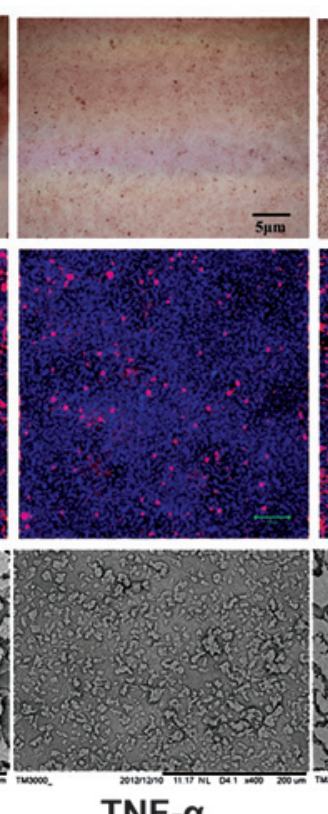
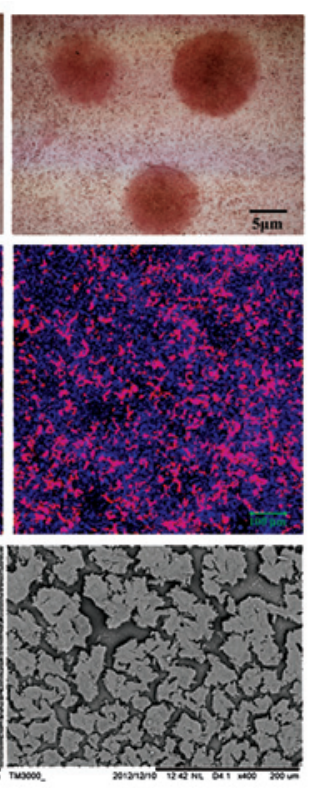

B

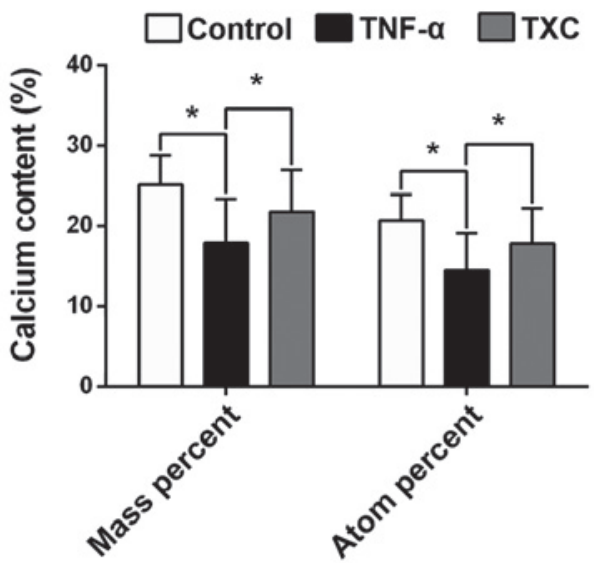

Figure 5. Observation and quantification of mineralized nodules in TNF- $\alpha$-injured OB-like cells. Compared with the TNF- $\alpha$ group, TXC treatment significantly promoted the secretion of cell mineralized nodules and increased the calcium content, which was observed using a phase contrast microscope, LSCM and SEM, and measured by EDS. (Aa) Alizarin red S staining was observed using phase contrast microscopy and (Ab) tetracycline staining was observed using an LSCM. (Ac) The morphological changes of mineralized nodules were also observed using an SEM. (B) EDS analysis was used for the quantification of the calcium content. For all groups, $n=10$. " $\mathrm{P}<0.05$. TXC, Tougu Xiaotong capsule; TNF- $\alpha$, tumor necrosis factor- $\alpha$; OB, osteoblast; LSCM, laser scanning confocal microscope; SEM, scanning electron microscope; EDS, energy dispersive spectroscopy.

of calcium salt, are a marker of mature OB differentiation. In order to explore the protective effect of TXC on OB mineralization, specific staining (alizarin red $\mathrm{S}$ and tetracycline staining) was performed and the morphological features of the mineralized nodules were observed under an SEM. As shown in Fig. 5A, mineralized nodule formation was inhibited in the TNF- $\alpha$ group, indicating that TNF- $\alpha$ inhibited the differentiation of the mature OB-like cells, whereas there was a clear increase in the number and width of mineralized nodules in the TXC group when compared with those in the TNF- $\alpha$ group, suggesting that TXC promoted the differentiation of mature OB-like cells. To further determine the effect of TXC on mineralized nodules, EDS analysis was used to quantify the calcium content. As shown in Fig. 5B, the calcium content (mass and atomic percentage) was significantly decreased in the TNF- $\alpha$ group compared with that in the control group, while the calcium content of the TXC group was significantly increased compared with that in the TNF- $\alpha$ group. This demonstrates the protective effect of TXC against TNF- $\alpha$-injured OB-like cell mineralization. 


\section{Discussion}

TXC is a clinically effective drug in the treatment of OA, which is able to alleviate osteoarthritic symptoms such as pain, swelling and limited joint mobility $(17,23,24)$. Previous studies have reported that the mechanisms underlying TXC treatment include the upregulation of $\mathrm{Bcl}-2$ and downregulation of p53 and caspase- 3 and -9 , as well as the regulation of Atg12/LC3 conjugation (17,25); however, the mechanisms through which TXC regulates osteoarthritic SB remodeling remain to be elucidated. The present study found that TXC was able to prevent TNF- $\alpha$-induced injuries of OB-like cells and promote cell proliferation and differentiation. This suggests that TXC may be able to protect bone osteogenesis from inflammation, which could be a molecular mechanism through which TXC regulates SB remodeling.

TNF- $\alpha$, as one of the key inflammatory factors, is generally considered to be responsible for the degeneration of articular cartilage and synovial membrane inflammation. TNF- $\alpha$ has been observed to affect the SB during the inflammatory process (10). Data have also shown that TNF- $\alpha$ can inhibit $\mathrm{OB}$ proliferation and differentiation and induce cellular apoptosis in vitro (13-16,20-22); therefore, TNF- $\alpha$ could directly or indirectly inhibit OB metabolism, leading to osteoarthritic SB alterations. The present study confirmed that TNF- $\alpha$ inhibited the viability of OB-like cells, promoted cellular mortality and apoptosis and inhibited cell differentiation by the downregulation of ALP activity, OCN secretion and nodule mineralization, in addition to reducing the calcium content of mineralized nodules, a finding that was consistent with a previous study (14). However, it was also found that ALP and OCN were not decreased as the treatment time was extended, which may have been due to the fact that the dose of TNF- $\alpha$ was not able to entirely inhibit cellular activities during the differentiation process.

The UMR-106 cell line is a clonal derivative of a transplantable rat osteosarcoma that is considered to be an OB-like cell line and has been used to study bone formation (26-28). In the present study, the protective effects of TXC against injuries in an OB-like cell line were investigated. Using MTT assay and LSCM analysis, it was found that TXC promoted the viability of the OB-like cells and reduced cellular mortality. In addition, the cellular nucleus and other organelles were better developed in the TXC-treated cells than in the untreated ones, which suggests that TXC promoted cell proliferation of the TNF- $\alpha$-injured OB-like cells. The results also demonstrated that TXC significantly upregulated the cellular activity of ALP, the secretion of OCN and the mineralization of nodules in TNF- $\alpha$-injured OB-like cells. Furthermore, the SEM observation and EDS analysis further confirmed that TXC promoted calcium secretion in TNF- $\alpha$-exposed OB-like cells. These findings indicate that TXC may be able to promote the differentiation and mineralization of OBs.

In conclusion, TXC protected an OB-like cell line from TNF- $\alpha$-induced injuries by promoting cell proliferation and differentiation. In agreement with our previous study $(18,19)$, it was found that TXC has the potential to regulate inflammation-induced alterations of SB. Further studies are required in order to investigate the mechanisms underlying the protective effects of TXC on OB injuries.

\section{Acknowledgements}

This study was supported by the Key Project of Fujian Province Department of Science and Technology (Grant no. 2012Y4006), the Natural Science Foundation of Fujian Province (Grant no. 2014J01356), the National Natural Science Foundation of China (Grant no. 81202836) and the Chen Keji Development Fund for Integrative Medicine (Grant no. CKJ2011004).

\section{References}

1. Glasson SS, Askew R, Sheppard B, Carito B, Blanchet T, Ma HL, Flannery CR, Peluso D, Kanki K, Yang Z, et al: Deletion of active ADAMTS5 prevents cartilage degradation in a murine model of osteoarthritis. Nature 434: 644-648, 2005.

2. Hayami T, Pickarski M, Zhuo Y, Wesolowski GA, Rodan GA and Duong le T: Characterization of articular cartilage and subchondral bone changes in the rat anterior cruciate ligament transection and meniscectomized models of osteoarthritis. Bone 38: 234-243, 2006.

3. Tat SK, Pelletier JP, Mineau F, Caron J and Martel-Pelletier J: Strontium ranelate inhibits key factors affecting bone remodeling in human osteoarthritic subchondral bone osteoblasts. Bone 49: 559-567, 2011

4. Kuroki K, Cook CR and Cook JL: Subchondral bone changes in three different canine models of osteoarthritis. Osteoarthritis Cartilage 19: 1142-1149, 2011.

5. Madry H, van Dijk CN and Mueller-Gerbl M: The basic science of the subchondral bone. Knee Surg Sports Traumatol Arthrosc 18: 419-433, 2010.

6. Castañeda S, Roman-Blas JA, Largo R and Herrero-Beaumont G: Subchondral bone as a key target for osteoarthritis treatment. Biochem Pharmacol 83: 315-323, 2012.

7. Imhof H, Sulzbacher I, Grampp S, Czerny C, Youssefzadeh S and Kainberger F: Subchondral bone and cartilage disease: A rediscovered functional unit. Invest Radiol 35: 581-588, 2000.

8. Muraoka T, Hagino H, Okano T, Enokida M and Teshima R: Role of subchondral bone in osteoarthritis development: A comparative study of two strains of guinea pigs with and without spontaneously occurring osteoarthritis. Arthritis Rheum 56: 3366-3374, 2007

9. Stannus O, Jones G, Cicuttini F, Parameswaran V, Quinn S, Burgess J and Ding C: Circulating levels of IL- 6 and TNF- $\alpha$ are associated with knee radiographic osteoarthritis and knee cartilage loss in older adults. Osteoarthritis Cartilage 18: 1441-1447, 2010

10. Hulejová H, Baresová V, Klézl Z, Polanská M, Adam M and Senolt L: Increased level of cytokines and matrix metalloproteinases in osteoarthritic subchondral bone. Cytokine 38: 151-156, 2007.

11. Kwan Tat S, Pelletier JP, Lajeunesse D, Fahmi H, Lavigne M and Martel-Pelletier J: The differential expression of osteoprotegerin $(\mathrm{OPG})$ and receptor activator of nuclear factor kappaB ligand (RANKL) in human osteoarthritic subchondral bone osteoblasts is an indicator of the metabolic state of these disease cells. Clin Exp Rheumatol 26: 295-304, 2008.

12. Tat SK, Pelletier JP, Vergés J, Lajeunesse D, Montell E, Fahmi H, Lavigne $\mathrm{M}$ and Martel-Pelletier J: Chondroitin and glucosamine sulfate in combination decrease the pro-resorptive properties of human osteoarthritis subchondral bone osteoblasts: A basic science study. Arthritis Res Ther 9: R117, 2007.

13. Xue LW, Zhang J, Wang XX, Bu T and Liu M: Effects of tumor necrosis factor- $\alpha$ on the growth of rat osteoblasts. Hua Xi Kou Qiang Yi Xue Za Zhi 27: 378-380, 2009 (In Chinese).

14. Tsukasaki M, Yamada A Suzuki D, Aizawa R, Miyazono A, Miyamoto Y, Suzawa T, Takami M, Yoshimura K, Morimura N, et al: Expression of POEM, a positive regulator of osteoblast differentiation, is suppressed by TNF- $\alpha$. Biochem Biophys Res Commun 410: 766-770, 2011.

15. Cunningham CC, Mills E, Mielke LA, O'Farrell LK, Lavelle E, Mori A, McCarthy GM, Mills KH and Dunne A: Osteoarthritis-associated basic calcium phosphate crystals induce pro-inflammatory cytokines and damage-associated molecules via activation of Syk and PI3 kinase. Clin Immunol 144: 228-236, 2012. 
16. Huang W, Shang WL, Wang HD, Wu WW and Hou SX Sirt1 overexpression protects murine osteoblasts against TNF-alpha-induced injury in vitro by suppressing the NF-kappaB signaling pathway. Acta Pharmacol Sin 33: 668-674, 2012.

17. Li XH, Wu MX, Ye HZ, Chen WL, Lin JM, Zheng LP and Liu XX: Experimental study on the suppression of sodium nitroprussiate-induced chondrocyte apoptosis by Tougu Xiaotong Capsule-containing serum. Chin J Integr Med 17: 436-443, 2011.

18. Huang YM, Chen WL, Liu XX, Huang MY, Lun RH, Li M, Xiao $\mathrm{CY}$ and Wu GW: Histochemical study of osteoarthritis treated by Tougu Xiaotong Granule. Zhongguo Zhong Yi Gu Shang Ke 19: 1-3, 2011 (In Chinese).

19. Li M, Guo YE, Liu XX, Wei SS, Chen WL, Lin JM, Huang YM, Huang MY and Wu ZL: Molecular mechanism of Tougu Xiaotong capsules for subchondral bone remodeling in knee osteoarthritis. Zhongguo Zu Zhi Gong Cheng Yan Jiu 16: 2669-2673, 2012 (In Chinese).

20. Minamitani C, Tokuda H, Adachi S, Matsushima-Nishiwaki R, Yamauchi J, Kato K, Natsume H, Mizutani J, Kozawa O and Otsuka T: p70 S6 kinase limits tumor necrosis factor-alpha-induced interleukin-6 synthesis in osteoblast-like cells. Mol Cell Endocrinol 315: 195-200, 2010.

21. Chae HJ, Chae SW, Kang JS, Bang BG, Cho SB, Park RK, So HS, Kim YK, Kim HM and Kim HR: Dexamethasone suppresses tumor necrosis factor-alpha-induced apoptosis in osteoblasts: Possible role for ceramide. Endocrinology 141: 2904-2913, 2000.

22. Mukai T, Otsuka F, Otani H, Yamashita M, Takasugi K, Inagaki $\mathrm{K}$, Yamamura $\mathrm{M}$ and Makino $\mathrm{H}$ : TNF-alpha inhibits BMP-induced osteoblast differentiation through activating SAPK/JNK signaling. Biochem Biophys Res Commun 356: 1004-1010, 2007.
23. Lin MN and Liu XX: Tougu Xiaotong Decoction for treating 30 cases of osteoarthritis of the knee. Fujian Zhong Yi Yao 36: 15-16, 2005 (In Chinese).

24. Zheng CS, Ye HZ, Xu XJ and Liu XX: Computational pharmacology study of tougu xiaotong granule in preventing and treating knee osteoarthritis. Chin J Integr Med 15: 371-376, 2009.

25. Li X, Liu F, Liang W, Ye H, Li H, Yu F, Chen J, Chen W, Lin R, Zheng C, et al: Tougu Xiaotong capsule promotes chondrocyte autophagy by regulating the Atg12/LC3 conjugation systems. Int J Mol Med 34: 545-552, 2014.

26. Dela Cruz A, Mattocks M, Sugamori KS, Grynpas MD and Mitchell J: Reduced trabecular bone mass and strength in mice overexpressing Ga11 protein in cells of theosteoblast lineage. Bone 59: 211-222, 2014.

27. Pon-On W, Charoenphandhu N, Teerapornpuntakit J, Thongbunchoo J, Krishnamra $\mathrm{N}$ and Tang IM: In vitro study of vancomycin release and osteoblast-like cell growth on structured calcium phosphate-collagen. Mater Sci Eng C Mater Biol Appl 33: 1423-1431, 2013.

28. Joung YH, Lim EJ, Darvin P, Chung SC, Jang JW, Do Park K, Lee HK, Kim HS, Park T and Yang YM: MSM enhances GH signaling via the Jak2/STAT5b pathway in osteoblast-like cells and osteoblast differentiation through the activation of STAT5b in MSCs. PLoS One 7: e47477, 2012. 